\title{
Social organization of the Asian elephant (Elephas maximus) in southern India inferred from microsatellite DNA
}

\begin{abstract}
Social organization of the Asian elephant (Elephas maximus) is not well understood in the absence of long-term studies of identified individuals. Adult Asian elephant females and their young offspring of both sexes form matriarchal groups, with pubertal males dispersing from natal groups, but whether these social groups represent families and whether males show locational or social dispersal were unknown. Using nuclear microsatellite loci amplified from dung-extracted DNA of free-ranging elephants in a large southern Indian population, we demonstrate that female-led herds comprise closely related individuals that are indeed families, and that males exhibit non-random locational dispersal.
\end{abstract}

Key words Asian elephant - Elephas maximus · Male dispersal - Microsatellite DNA · Relatedness · Social organization $\cdot$ Southern India

\section{Introduction}

Unlike the African savannah elephant (Loxodonta africana africana) for which at least one population (at Amboseli, Kenya) has been under long-term observation (Moss 2001), social organization of the endangered Asian elephant (Elephas maximus) has been little studied (see Sukumar 1989; Baskaran 1998; Fernando and Lande 2000). In the African savannah elephant, a multi-tiered social organization exists (Moss 1988), the basic unit of which is the mother-offspring unit, with two to three such units comprising a family led by a matriarch (Douglas-Hamilton 1972). A few related families that show significant social association amongst themselves constitute "kinship groups" (Douglas-Hamilton 1972) or "bond groups" (Moss and

T.N.C. Vidya $\cdot$ R. Sukumar $(\triangle)$

Centre for Ecological Sciences, Indian Institute of Science, Bangalore, 560012, India

Tel. +91-80-23600382; Fax +91-80-23602280

e-mail: rsuku@ces.iisc.ernet.in
Poole 1983), while bond groups that share a dry season home range constitute a "clan" (Moss and Poole 1983). Pubertal males, 9-18 years of age, leave their natal family group through a gradual process that may take up to 4 years (Lee and Moss 1999). Adult males are largely solitary, but may associate with female groups or form loose associations with other males (Croze 1972), depending on their age and sexual state (Poole and Moss 1981).

Studies of the Asian elephant in tropical dry habitats have confirmed the existence of basic social units comprising mother and dependent offspring (McKay 1973; Sukumar 1989, p. 50). Associations of two or more motheroffspring units have been variously described as "family groups" (Fernando and Lande 2000) in southeastern Sri Lanka, and as "family groups", "joint family groups" and "clans" (larger associations of family groups) in southern India (Sukumar 1989, 1994; Baskaran et al. 1995). However, terminology apart, in the absence of any long-term study of identified individuals, it has not been demonstrated that such groups are indeed comprised of closely related adult females. Social groups formed by females could be a strategy to improve the survival of their offspring through protection against predators or allomothering (Gadgil and Nair 1984; Lee 1991). When such females are closely related, this strategy would also increase their inclusive fitness (Hamilton 1964), as opposed to individuals that are not closely related associating together to enhance foraging efficiency (as in river otters; Blundell et al. 2004) or to decrease predation risk (as in eastern grey kangaroos; Banks 2001). Studies of behaviour in the African savannah elephant have shown that family members are closely associated and spend 70-90\% of their time together (Moss 1988; Lee 1991). On the other hand, studies of radio-collared elephants in Asia have shown a much lower association between members of groups, with $18-29 \%$ in southeastern Sri Lanka (Fernando and Lande 2000). Different definitions of a "family group" used by observers in the two continents and variable habitat visibility for observation may confound this comparison to some extent. However, the much lower association between members of groups suggests lesser cohesiveness within groups in the Asian elephant (in comparison 
to the African savannah elephant), which may be due to a lower degree of relatedness between the constituent members.

While it is known that pubertal Asian elephant males disperse from their natal groups (Sukumar 1989, p. 51; Desai and Johnsingh 1995), it has not been clear whether they move away from their natal range (locational dispersal) (Desai and Johnsingh 1995) or whether they remain in their natal range and move long distances only to mate (social dispersal) (Fernando and Lande, unpublished data in Sukumar 2003). This would require following prepubertal males over several years through radio-telemetry, documenting their ranging patterns prior to and after dispersal. Patterns of male dispersal have not been well studied even in the African elephant, though there are indications that both types of dispersal may exist (Poole 1996, p. 67). Either of these scenarios of male dispersal is expected to produce an absence of nuclear genetic differentiation across locations; this is indeed the pattern observed in the NilgirisEastern Ghats region in southern India (Vidya et al. 2005). But while locational dispersal is expected to bring about an absence of relatedness between adult females and adult males within locations, social dispersal is expected to result in adult females and adult males within locations being related to some degree.

Given this knowledge of social organization of African and Asian elephants, we carried out this study to specifically test the following null hypotheses.

1. Adult female elephants within a group are random associations of adult females in the region (relatedness is zero). Rejection of the null hypothesis would imply that matriarchal social groups of elephants are composed of related individuals.

2. Male elephants disperse in a random fashion from their natal home range (that is, show random locational dispersal). This would imply that relatedness between adult males and adult females as well as between adult males within a location would be zero. Rejection of the null hypothesis would give rise to two alternate hypotheses: first, that male elephants largely remain in their natal home range and show social dispersal outside for mating (when in musth); and second, that related (pre-pubertal) males within a matriarchal social group disperse together (biased locational dispersal).

In a study based on mitochondrial DNA (mtDNA) haplotypes in the Asian elephant, Fernando and Lande (2000) showed that all the adult females of a social group had the same haplotype, indicative of shared maternal ancestry. However, given the mutation rate (of $3 \%$ per million years) (Fleischer et al 2001) of the mitochondrial segment they used, it is not possible to discriminate between closelyrelated females and females that are not related to one another (with a nuclear relatedness of/close to zero), but share a common maternal ancestor thousands of years ago. We therefore use nuclear microsatellite DNA, which has a much higher mutation rate $\left(10^{-5}-10^{-2}\right.$; see Jarne and Lagoda 1996) than that of mtDNA. Analysing microsatellites ampli- fied from dung-extracted DNA of free-ranging animals, we examine whether adult females of a social group are related to one another, whether males show locational dispersal or social dispersal, and whether adult males within locations are related to one another. This is the first study utilising nuclear genetic relatedness between individuals to infer patterns of social organization in either Asian or African elephants.

\section{Study area}

Samples for this study came from seven locations in the Nilgiris-Eastern Ghats region of southern India, which harbours the world's single largest contiguous population of Asian elephants with an estimated 9000 individuals (AERCC 1998; unpublished census data of the state forest departments for 2002). This population, henceforth referred to as the Nilgiri population, ranges across an area of approximately $15,000 \mathrm{~km}^{2}(100-2400 \mathrm{~m}$ above mean sea level) across the Western and southern Eastern Ghats mountain ranges, covering a wide range of tropical habitat types from dry thorn forest through deciduous forests to evergreen forests. The focus of the study was Mudumalai Wildlife Sanctuary, a location with one of the highest elephant densities (2-4 elephants $/ \mathrm{km}^{2}$; AERCC 1998) in the country situated centrally in the Nilgiri region, but samples

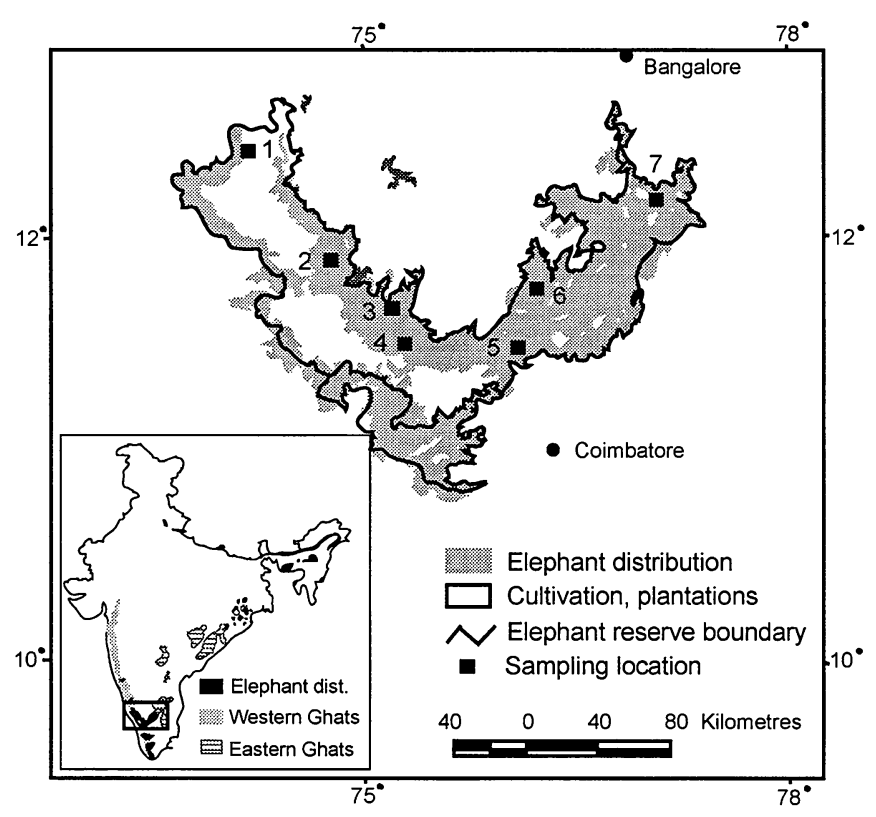

Fig. 1. Asian elephant (Elephas maximus) distribution in the NilgirisEastern Ghats region, southern India. For the purpose of administration, the region is divided into two Project Elephant Reserves, as demarcated by the dark lines. Sampling locations are shown; the locations are 1 Madikeri Forest Division, 2 Nagarahole National Park, 3 Bandipur National Park, 4 Mudumalai Wildlife Sanctuary, 5 Satyamangalam Forest Division, 6 Biligiri Rangaswamy Temple (BRT) Wildlife Sanctuary, and 7 Hosur Forest Division. Inset Map of India showing elephant distribution, the Eastern and Western Ghats, and the location of the Nilgiris-Eastern Ghats region 
were also collected from six other locations shown in Fig. 1.

\section{Materials and methods}

Since obtaining tissue or blood from free ranging, endangered, large mammals like elephants is extremely difficult in practice, we sampled noninvasively. Free-ranging elephant herds were tracked, individuals identified, and dung samples collected (sampling details in Table 1) upon observed defecation. Individual identification was based on the animal's estimated age (based on height and other morphological characteristics), sex, and various features like tusk (in males), tush (in tuskless males and females), ear, and tail, characteristics and body lumps or other natural markings (see Sukumar 1989, pp. 224-226). Samples were collected from the outer most layer of dung, which would contain sloughed-off epithelial cells and have the least degraded DNA. Samples were collected into 95\% ethanol and stored at ambient temperature.

DNA was extracted from dung by digesting about $0.5 \mathrm{~g}$ of dung with Proteinase K and a Tris-EDTA-SDS buffer, extracting with phenol/chloroform/isoamyl alcohol, and purifying using QIAGEN gel purification columns (see Fernando et al. 2003). Six microsatellite loci were amplified: tri- and tetra- nucleotide repeats, EMX-1, EMX-2, EMX-3, and EMX-4, isolated from E. maximus (Fernando et al. 2001), and dinucleotide loci, LafMS02 and LafMS03, isolated from Loxodonta africana africana (Nyakaana and Arctander 1998). Microsatellite loci were amplified in 12.5 $\mu \mathrm{l}$ PCR reactions, using $2 \mu \mathrm{l}$ DNA extract. PCR products were electrophoresed on a $5.6 \%$ polyacrylamide gel in an ABI Prism 377 DNA Sequencer, and the samples tracked and scored using the ABI Gene Scan analysis software v.3.1 (PE Applied Biosystems 1998). Dedicated instruments and areas were used for low-copy number DNA samples in order to minimize errors in genotyping (also see Fernando et al. 2003; Vidya et al. 2005).

Table 1. Number of individual Asian elephants (Elephas maximus) sampled from different locations; $A F$ adult female; $A M$ adult male; $S A M$ sub-adult male. The geographic positions of the sampling locations and their complete names are given in Fig. 1. Out of the 40 adult females sampled in Mudumalai, 29 were from distinctly identified "family" groups and only those were used in the analysis of relatedness between adult females within groups. Adults are defined as individuals over the age of 15 years and sub-adults as individuals of 5-15 years

\begin{tabular}{lrrl}
\hline Location & AF & AM & SAM \\
\hline 1. Madikeri & 8 & 7 & 0 \\
2. Nagarahole & 14 & 11 & 2 \\
3. Bandipur & 7 & 2 & 2 \\
4. Mudumalai & 40 & 12 & 2 \\
5. Satyamangalam & 9 & 0 & 0 \\
6. BRT & 14 & 2 & 0 \\
7. Hosur & 6 & 2 & 0 \\
Total & 98 & 36 & 6 \\
\hline
\end{tabular}

The loci used were already known to be in Hardy Weinberg equilibrium and in linkage equilibrium in this population (Vidya et al. 2005) and the baseline allele frequencies in the population are listed in Table 2. Queller and Goodnight's (1989) measure of relatedness that is based on the probability of identity by descent was used to estimate the relatedness between individuals. The relatedness $r$ between individuals within groups was calculated as

$r=\frac{\sum_{i} \sum_{j} \sum_{k} \sum_{a}\left(p_{i(-j) m}-\bar{p}_{(-i) m}\right)}{\sum_{i} \sum_{j} \sum_{k} \sum_{a}\left(p_{i j m}-\bar{p}_{(-i) m}\right)}$,

where $i, j$, and $k$, index groups, individuals within each group, and loci, respectively, $a$ indexes allelic position, therefore having a maximum value of two in a diploid organism, $p_{i(-j) m}$ is the frequency of the allele $m$ in group $i$ excluding the $j$ th individual, $p_{i j m}$ includes the $j$ th individual, and $\bar{p}_{(-i) m}$ is the population mean frequency of $m$ corrected for sample size by excluding the $i$ th group being summed over. Relatedness between groups, of group $x$ to group $y$, was estimated as

$r=\frac{\sum_{x} \sum_{k} \sum_{a}\left(p_{y m}-\bar{p}_{m}^{*}\right)}{\sum_{x} \sum_{k} \sum_{a}\left(p_{x m}-\bar{p}_{m}^{*}\right)}$,

where $\mathrm{p}_{y m}$ and $\mathrm{p}_{x m}$ are the frequencies of allele $\mathrm{m}$ in group $\mathrm{x}$ and $\mathrm{y}$, respectively, $\bar{p}_{m}^{*}$ is the population mean frequency corrected for sample size by excluding the xth group currently being summed over as well as its partner groups (y). These calculations were performed using the software Relatedness 5.0 (Goodnight and Queller 1999). Standard Error was obtained by a jack-knifing procedure across loci, as implemented in the software. A set of samples of 20 identified mother-offspring pairs from Mudumalai Wildlife Sanctuary was used to check for Mendelian inheritance of the microsatellite loci used. This set of individuals was not used in the subsequent analyses as this set comprised of

Table 2. Allele frequencies in the Nilgiri elephant population

\begin{tabular}{lll}
\hline Locus & Allele & Frequency \\
\hline EMX-1 & 135 & 0.560 \\
& 147 & 0.004 \\
EMX-2 & 150 & 0.436 \\
& 219 & 0.437 \\
EMX-3 & 225 & 0.563 \\
EMX-4 & 238 & 0.093 \\
& 254 & 0.907 \\
LafMS02 & 351 & 0.309 \\
& 375 & 0.272 \\
& 387 & 0.419 \\
& 131 & 0.004 \\
LafMS03 & 133 & 0.046 \\
& 135 & 0.313 \\
& 137 & 0.401 \\
& 141 & 0.237 \\
& 135 & 0.007 \\
& 137 & 0.426 \\
& 139 & 0.346 \\
& 149 & 0.121 \\
& 151 & 0.029 \\
& 155 & 0.070 \\
\hline
\end{tabular}


Table 3. Results of relatedness between individuals: criteria for individuals used in the analyses $(A F$ adult female; $A M$ adult male; $S A M$ subadult male; $A n y$ : adult, subadult, or juvenile, male or female), grouping unit and number, number of individuals sampled ( $n_{\mathrm{x}}, n_{\mathrm{y}}$; in case of only one criterion of individuals being used, $n_{\mathrm{x}}$ and $n_{\mathrm{y}}$ are identical), relatedness value $(R)$, standard error, and the $95 \%$ confidence intervals for the relatedness value

\begin{tabular}{|c|c|c|c|c|c|}
\hline Individual criterion & Grouping unit & No. of grouping units & $n_{\mathrm{x}}$ & $n_{\mathrm{y}}$ & $R$ \\
\hline $\mathrm{AF}$ & Within the same "family" group & 13 groups & 29 & 29 & 0.365 \\
\hline $\mathrm{AF}$ & Across "family" groups but within the same location & 7 locations & 98 & 98 & 0.041 \\
\hline AF vs AM & Within the same location & 6 locations & 88 & 36 & 0.072 \\
\hline AF vs SAM & Within the same location & 3 locations & 60 & 6 & 0.028 \\
\hline $\mathrm{AM}$ & Within the same location & 6 locations & 36 & 36 & 0.205 \\
\hline Any & Within the same location & 7 locations & 140 & 140 & 0.009 \\
\hline Any & Any two different locations & 7 locations & 140 & 140 & 0.002 \\
\hline
\end{tabular}

mother-dependent offspring pairs as opposed to relatedness between adult females that we were interested in.

\section{Results}

Each of the 20 mother-offspring pairs showed shared alleles at all loci and the average relatedness $( \pm 95 \%$ confidence interval) between adult females and their offspring as calculated using the Relatedness software was $0.437 \pm 0.051$. The average relatedness ( $\pm 95 \%$ confidence interval) between adult females within identified family groups in Mudumalai Wildlife Sanctuary was $0.37 \pm 0.159$ ( $n=13$ family groups). This relatedness is therefore statistically greater than zero, but not different from the relatedness between mother-offspring pairs as the confidence intervals overlap. These family groups had a median group size of eight individuals, and two, or occasionally three, adult females were sampled per family group. The average relatedness between adult females across groups but within a location was $0.04 \pm 0.038$ (total $n_{\text {adult females }}=98,7$ locations: Mudumalai Wildlife Sanctuary, $n=40$; BRT Wildlife Sanctuary, $n=14$; Hosur Forest Division, $n=6$; Nagarahole National Park, $n=14$; Madikeri Forest Division, $n=8$; Satyamangalam Forest Division, $n=9$; Bandipur National Park, $n=7$ ), which is therefore statistically different from zero (Table 3). The average relatedness between adult females across groups and across locations was not different from zero ( $R=-0.010 \pm 0.039, n_{1}=n_{2}=87,7$ locations).

The average relatedness between adult females and adult males within a location $\left(R=0.072 \pm 0.081, n_{\text {adult females }}=88\right.$, $n_{\text {adult males }}=36,6$ locations) and the relatedness between adult females and subadult males within a location $\left(R=0.028 \pm 0.150, n_{\text {adult females }}=60, n_{\text {subadult males }}=6,3\right.$ locations) were not statistically different from zero. However, the relatedness between adult males within locations was $0.20 \pm 0.102$ ( $n=36,6$ locations), which is different from zero (Table 2). Based on the $95 \%$ confidence intervals, this relatedness is statistically different from the relatedness between mother-offspring pairs, but not from the relatedness between adult females within social groups. The average relatedness between any two individuals within or across locations was not statistically different from zero ( $R=0.002 \pm 0.024, n=140,7$ locations).

\section{Discussion}

This study of relatedness is the first of its kind in elephants and gives rise to the following inferences. The relatedness $(0.37 \pm 0.159)$ between adult females within elephant groups is not different from that between mother-offspring pairs, suggesting that most of these adult females are closely related as mother-daughters or full sisters. The lower end (0.37-0.159) of this relatedness spectrum may correspond to half-sisters. Thus, this is the first demonstration that the basic Asian elephant social group represents a "family group", as has been demonstrated through direct observations in the African savannah elephant (Moss and Poole 1983). The high relatedness between adult females within groups also suggests that there is no inter-group transfer of females among elephants, unlike in some cetaceans (Amos et al. 1993; Richard et al. 1996) and primates (Brockelman et al. 1998; Morin et al. 1994). This study included relatively small elephant groups with 2-3 adult females. Associations of such groups are known from this population (Sukumar 1989; Baskaran 1998) and these groups may possibly be related, as suggested by the closer relatedness between adult females within locations, indicative of female philopatry. A more detailed study involving associations of family groups and the relatedness between them is suggested in order to understand further hierarchical levels of social organization that may exist.

The absence of significant relatedness $(R>0)$ between adult females and sub-adult or adult males within locations is suggestive of locational male dispersal in this elephant population. In the event of social dispersal, given the low probability of capturing in our sample males that have moved outside of their natal range to mate, significant relatedness $(R>0)$ between males and females within a location should be observed. Independent data from central and northeastern India (Vidya et al., unpublished data) on the presence of adult males of a different mitochondrial haplotype in areas with adult females of a common haplotype also agree with the locational dispersal hypothesis. Unlike social dispersal, locational dispersal is thought to have a high cost associated with it in terms of increased vulnerability to predation in addition to unfamiliar foraging grounds (see Isbell and Van Vuren 1996). However, the first factor (predation) does not apply to sub-adult elephants, and the cost of for- 
aging in an unfamiliar environment may be decreased by making gradual changes in home range (see Isbell and Van Vuren 1996) as is believed to be made in the Asian elephant (Desai and Johnsingh 1995). Locational dispersal may increase accessibility to unrelated mates (see Greenwood 1980), as a pre-reproductive period spent in the area where it is going to mate may keep the male better informed than a period spent in its natal home range with related females. This may be particularly important to the male's reproductive success since female elephants show long inter-calving intervals of about 4-5 years (Sukumar 2003, p. 260) and come into oestrous only for 2-4 days every 4 months (Sukumar 2003, p. 96). Thus, locational dispersal is possibly a high cost-high gain strategy. It would be interesting to understand the ecological and ethological correlates of the two types of dispersal; for instance, to examine if social dispersal exists in populations with highly skewed (towards females) adult sex ratios where male-male competition is considerably lowered, or in areas with highly heterogeneous habitats where the cost of locational dispersal may be high.

While the high relatedness between adult males within locations, which implies non-random dispersal of related males, is a surprising finding, we conjecture that advantage may accrue from this strategy in situations of male-male conflict with new males that are encountered, a testable hypothesis for future study. Biased dispersal, in the form of dispersal along with natal group peers, has been recorded in rhesus macaques (Meikle and Vessey 1981) and vervet monkeys (Cheney 1983; Cheney and Seyfarth 1983), and appears to facilitate integration into new groups by reducing aggression. The role of a companion of either sex during dispersal has also been recorded in the white rhinoceros (Shrader and Owen-Smith 2002). There is no significant genetic differentiation among elephants between locations within the Nilgiris (Vidya et al. 2005). Therefore, the relatedness of adult elephant males within locations that we observe is not an artefact of different locations having different genetic compositions. The fairly high relatedness of adult males within locations possibly explains our field observations of several males coming into musth simultaneously in the same area (unpublished data at the Centre for Ecological Sciences), with apparently no aggressive interactions between them. However, this part of the study is preliminary and a more detailed study of behaviour and relatedness, sampling in particular sub-adult males, which would be in the dispersing stage, and sampling in populations with varying habitat attributes, is indicated for a better understanding of male dispersal in this species.

Acknowledgements Fieldwork was funded by the Ministry of Environment and Forests, Government of India and samples were collected with research permissions from the state forest departments of Tamil Nadu and Karnataka. The molecular work was supported by the United States Fish and Wildlife Service-Asian Elephant Conservation Fund (USFWS-AECF) and the Columbia University Laboratory for Genetic Investigation and Conservation (LOGIC). We thank Prof. Don Melnick and Dr. Prithiviraj Fernando of Columbia University for their support and help. Dr. Uma Ramakrishnan collected the set of mother-offspring samples we used to test for Mendelian inheritance of microsatellite loci. Mr. K. Krishna, Mr. R. Mohan, and several forest department trackers provided field assistance. We thank two anony- mous reviewers whose comments helped us in improving this manuscript. This work constitutes part of the doctoral thesis of T.N.C.V.

\section{References}

Amos B, Schlötterer C, Tautz D (1993) Social structure of pilot whales revealed by analytical DNA profiling. Science 260:670-672

AERCC (1998) The Asian elephant in southern India: a GIS database for conservation of Project Elephant Reserves. Asian Elephant Research and Conservation Centre, Bangalore

Banks PB (2001) Predation-sensitive grouping and habitat use by eastern grey kangaroos: a field experiment. Anim Behav 61:1013-1021

Baskaran N (1998) Ranging and resource utilization by Asian elephant (Elephas maximus Linnaeus) in Nilgiri Biosphere Reserve, South India. PhD Thesis, Bharathidasan University, Tamilnadu India

Baskaran N, Balasubramanian S, Swaminathan S, Desai AA (1995) Home range of elephants in the Nilgiri Biosphere Reserve, south India. In: Daniel JC, Datye HS (eds) A week with elephants. Bombay Natural History Society and Oxford University Press, Bombay, pp 296-313

Blundell GM, Ben-David M, Groves P, Bowyer RT, Geffen E (2004) Kinship and sociality in coastal river otters: are they related? Behav Ecol 15:705-714

Brockelman WY, Reichard U, Treesucon U, Raemakers JJ (1998) Dispersal, pair formation and social structure in gibbons (Hylobates lar). Behav Ecol Sociobiol 42:329-339

Cheney DL (1983) Promixate and ultimate factors relationed to the distribution of male migration. In: Hinde R (ed) Primate social relationships. Blackwell, Boston, pp 241-249

Cheney DL, Seyfarth RM (1983) Nonrandom dispersal in free-ranging vervet monkeys: social and genetic consequences. Am Nat 122:392412

Croze H (1972) A modified photogrammetric technique for assessing age-structures of elephant populations and its use in Kidepo National Park. East Afr Wildl J 10:91-115

Desai AA, Johnsingh AJT (1995) Social organization and reproductive strategy of the male Asian elephant (Elephas maximus). Abstract in: Daniel JC, Datye HS (eds) A week with elephants. Bombay Natural History Society and Oxford University Press, Bombay, pp 532

Douglas-Hamilton I (1972) On the ecology and behaviour of the African elephant: the elephants of Lake Manyara. DPhil thesis, University of Oxford

Fernando P, Lande R (2000) Molecular genetic and behavioural analysis of social organization in the Asian elephant (Elephas maximus). Behav Ecol Sociobiol 48:84-91

Fernando P, Vidya TNC, Melnick DJ (2001) Isolation and characterization of tri- and tetranucleotide microsatellite loci in the Asian elephant, Elephas maximus. Mol Ecol 1:232-234

Fernando P, Vidya TNC, Rajapakse C, Dangolla A, Melnick DJ (2003) Reliable non-invasive genotyping: fantasy or reality? J Hered 94:115-123

Fleischer R, Perry E, Muralidharan K, Stevens E, Wemmer C (2001) Phylogeography of the Asian elephant (Elephas maximus) based on mitochondrial DNA. Evolution 55:1882-1892

Gadgil M, Nair PV (1984) Observations on the social behaviour of free-ranging groups of tame Asiatic elephant (Elephas maximus Linn.). Proc Indian Acad Sci (Anim Sci) 94:575-586

Goodnight KF, Queller DQ (1999) Relatedness version 5.0. Available from http://gsoft.smu.edu/Gsoft.html

Greenwood PJ (1980) Mating systems, philopatry and dispersal in birds and mammals. Anim Behav 28:1140-1162

Hamilton WD (1964) The genetical evolution of social behaviour. J Theor Biol 7:1-52

Isbell LA, Van Vuren D (1996) Differential costs of locational and social dispersal and their consequence for female group-living primates. Behaviour 133:1-36

Jarne P, Lagoda PJL (1996) Microsatellites, from molecules to populations and back. Trends Ecol Evol 11:424-429

Lee P (1991) Social Life. In: Eltringham SK (ed) The illustrated encyclopedia of elephants. Salamander, London, pp 48-63

Lee PC, Moss CJ (1999) The social context for learning and behavioural development among wild African elephants. In: Box HO, 
Gibson KR (eds) Mammalian social learning: comparative and ecological perspectives. Cambridge University Press, Cambridge, pp $102-125$

McKay GM (1973) The ecology and behavior of the Asiatic elephant in southeastern Ceylon. Smithson Contrib Zool 125:1-113

Meikle DB, Vessey SH (1981) Nepotism among rhesus monkey brothers. Nature 294:160-161

Morin PA, Moore JJ, Chakraborty R, Jin L, Goodall J, Woodruff DS (1994) Kin selection, social structure, gene flow, and the evolution of chimpanzees. Science 265:1193-1201

Moss CJ (1988) Elephant memories: thirteen years in the life of an elephant family. William Morrow, New York

Moss CJ (2001) The demography of an African elephant population (Loxodonta africana) population in Amboseli, Kenya. J Zool Lond 255:145-156

Moss CJ, Poole JH (1983) Relationships and social structure of African elephants. In: Hinde R (ed) Primate social relationships. Blackwell, Boston, pp 315-325

Nyakaana S, Arctander P (1998) Isolation and characterization of microsatellite loci in the African elephant, Loxodonta africana. Mol Ecol 7:1436-1437

PE Applied Biosystems (1998) ABI GeneScan Analysis Software v3.1. PE Applied Biosystems, Foster City
Poole JH (1996) Coming of age with elephants. Hyperion Press, New York

Poole JH, Moss CJ (1981) Musth in the African elephant, Loxodonta africana. Nature 292:830-831

Queller DC, Goodnight KF (1989) Estimating relatedness using genetic markers. Evolution 43:258-275

Richard KR, Dillon MC, Whitehead H, Wright JM (1996) Patterns of kinship in groups of free-living sperm whales (Physeter macrocephalus) revealed by multiple molecular genetic analyses. Proc Natl Acad Sci USA 93:8792-8795

Shrader AM, Owen-Smith N (2002) The role of companionship in the dispersal of white rhinoceroses (Ceratotherium simum). Behav Ecol Sociobiol 52:255-261

Sukumar R (1989) The Asian elephant: ecology and management. Cambridge University Press, Cambridge

Sukumar R (1994) Elephant days and nights: ten years with the Indian elephant. Oxford University Press, New Delhi

Sukumar R (2003) The living elephants: evolutionary ecology, behavior, and conservation. Oxford University Press, New York

Vidya TNC, Fernando P, Melnick DJ, Sukumar R (2005) Population differentiation within and among Asian elephant (Elephas maximus) populations in southern India. Heredity 94:71-80 